\title{
Application of dynamic programming for guiding IPM on groundnut leafminer in India
}

\author{
N. J. Dudley, R. A. E. MuelleR* and J. A. Wightman $\dagger$ \\ Department of Economics, University of New South Wales, Kensington, NSW, 2033, Australia; \\ *Resource Management and $\dagger$ Legumes Program, International Crops Research Institute for the Semi- \\ Arid Tropics (ICRISAT), Patancheru, Andhra Pradesh 502 324, India
}

\begin{abstract}
A simulation model of the population dynamics of groundnut leafminer (GLM), Aproaerema modicella (Deventer) was built in the early stages of an IPM research project. The model was specified with experimental and farm management data from India. It was linked to a dynamic programming procedure which indicated the number of insecticide applications needed to optimize income over ranges of natural mortality and host-plant resistance, and extended to include the initial level of the GLM population, mortality caused by insecticides to natural enemies, the efficacy of insecticide application, and groundnut prices. Model results indicated that future research should evaluate the effectiveness of farmers' insecticide applications. The initial population density had a significant influence on subsequent levels of 'damage'. Insecticide mortality of natural enemies and groundnut prices were of less importance.
\end{abstract}

KEYWORDS: Groundnut leafminer; host-plant resistance; chemical control; natural control; control interactions; simulation; dynamic programming

\section{Introduction}

Applied pest management research in developing countries is orientated towards providing pest control options that are likely to be adopted by small farmers and that are acceptable, to governments. The aim is usually to replace insecticides with alternative pest control procedures that do not require substantial cash inputs and infrastructure for their distribution, that have little deleterious environmental side-effects, and that do not require foreign exchange.

Alternative pest control methods are plant resistance or tolerance to target insects, natural control and the modification of cultural practices. At present, these methods alone rarely avoid immediate pest losses as effectively as control with insecticides. Research has either to augment the effectiveness of control methods applied alone, or to integrate methods that complement the use of pesticides.

Such research programmes, which cost time and other resources, should not aim at maximizing the effectiveness of individual control methods. This would result in misallocation of resources when the returns, in terms of yield loss avoided or control costs saved, do not increase continuously or at a lower rate than with increasing research on other controls.

For instance, agronomically acceptable genotypes are often less pest resistant than agronomically unacceptable genotypes. Breeding programmes for increasing resistance or for improving agronomic characteristics are long term, and compete for breeders' resources. The incremental pest resistance in a crop that is usually treated with pesticides may be wasted when it does not need fewer pesticide applications.

Furthermore, it is imprudent to breed for very high levels of host-plant resistance when the protection obtained could be achieved by lower levels of resistance combined with protection through natural enemies. The question is 'how much' of each control component should be employed in integrated pest control. Answering this becomes more difficult as the number of components and combinations increases. Quantitative methods are required to handle this complexity.

We describe and report results from a model used in the early stages of a research project in which mortality due to natural enemies (MNE), host-plant resistance (HPR) and insecticides are evaluated as means to control a serious pest of groundnut in Asia, especially India. The model consists of a sub-model with a single difference equation to simulate pest density, and yield, cost and return functions to calculate net returns from a groundnut crop. The simulation sub-model is linked to a dynamic programming (DP) sub-model to optimize farmers' insecticide application decisions. Applications of DP to pest management problems have been reviewed by Feldman and Curry (1982) and Kennedy (1981). Recent pest management applications have been reported by Onstad and Rabbinge (1985), Taylor 
and Burt (1984), and Shoemaker and Onstad (1983). In none of the applications has DP been used to evaluate HPR or to guide research.

\section{The problem}

Groundnut is a major oilseed crop in India and accounts for roughly one-third of her edible oil production. Only about two-thirds of India's edible oil consumption is met by domestic production and the expense of oil imports has been rising. India is therefore anxious to increase her groundnut production. Avoiding losses caused by the groundnut leafminer (GLM) Aproaerema modicella (Deventer) (Lepidoptera: Gelechiidae) is one option. This insect is responsible for substantial losses in India every year, particularly where rain-fed groundnut following irrigated groundnut provides ideal conditions for population build-up (Wightman and Amin, 1988).

The insecticides currently available can control GLM, but we have little information about farmers' practices and the control achieved in farmer's fields. Mohammad (1981) reported that GLM has 25 species of parasite. There are also a number of groundnut genotypes with resistance to the pest (ICRISAT, 1986). GLM has three or four discrete generations per season, depending on the timing of the initial infestation and the duration of the crop. A review of our existing data from low-intensity (once per generation) sampling and from one season's weekly sampling (unpublished data) indicated that there was about a 20-fold generation-to-generation increase. This estimate was for a susceptible cultivar and excluded the highly variable (5-95\%) influence of larvae parasites.

GLM has been selected by ICRISAT as a target insect for developing a pest management programme based on HPR that requires fewer insecticide applications. We found it necessary to apply the small amount of field data at our disposal to set research goals and to identify research needs. The questions asked were:

1. What level of HPR is needed to obviate the need for insecticide application and how is that level influenced by the market price for groundnuts and MNE of the pest?

2. How sensitive is the desirable level of HPR to changes in the initial density of the pest?

3. How do the effectiveness of farmers' insecticide application procedures and HPR interact, with respect to the required number of pesticide applications?

4. If an insecticide application kills a proportion of natural enemies, how does this influence the desirable level of HPR?

\section{The pest control decision model}

The farm decision model developed in this section is normative and deterministic. It determines the opti- mal chemical-control strategy for one hectare of irrigated groundnut infested by GLM. The model assumes rational decision-makers who understand the implications of a decision to apply insecticide. The scope of the model is limited to the groundnut enterprise. Thus, ramifications of changes in the returns from groundnuts on farm resource allocation are not considered.

The bionomic data we employ are based on data collected in the field. However, several assumptions had to be made which may be far-reaching, and limit the validity of the model. Therefore we regard our model to be applicable for guiding research but not for providing recommendations for farmers.

\section{GLM bionomics}

All GLM in a field at time $t$ are of similar maturity; thus time periods and generations of GLM coincide. Migration of GLM to and from a field is negligible. The GLM density at the beginning of generation $t+1$ therefore depends on the density at the beginning of generation $t$, the reproduction rate, the level of control achieved with insecticides, MNE, and the impact of HPR on density growth. As chemical control, MNE, and HPR reduce the natural density growth rate, GLM density $(L)$ can be expressed as a multiplicative differential equation

$$
L_{t+1}=a \phi \beta_{t}\left(1-\theta_{t}\right) L_{t}
$$

where:

$a$ is the constant natural reproduction rate;

$\phi$ inversely reflects the impact of HPR so that high values of $\phi$ indicate little HPR;

$\beta_{t}$ is the survivorship from MNE, and

$\theta_{t}$ is the mortality caused in period $t$ by insecticides.

This mortality depends on the decision to apply insecticides for GLM control so that:

$\theta_{t}=\theta \kappa_{t}$

where:

$\theta$ is the fraction of GLM destroyed when an insecticide is applied, the kill efficacy, and

$K_{t}$ is a binary variable indicating spray $\left(K_{t}=1\right)$ or no spray $\left(K_{t}=0\right)$ in generation $t$.

Natural enemies reduce the size of the GLM density by a fraction $\gamma$, so that only $\beta=1-\gamma$ GLM survive. The effectiveness of na tural enemies, all of which are assumed to be arthropods, may, in turn, be affected by chemical control of GLM. This effect is most likely to occur in the generation after insecticide has been applied. The delayed effect of insecticide application on beneficial insects is specified as:

$\beta_{t}=1-\alpha_{t} \gamma$ 
with

$\alpha_{t}=\left\{\begin{array}{lll}1 & \text { if } & K_{t-1}=0 \\ \alpha & \text { if } & K_{t-1}=1\end{array}\right.$

where:

$\gamma$ is GLM mortality due to natural enemies when the density of beneficial insects has not been reduced by insecticides, and

$\alpha$ is the proportional reduction in GLM one generation after insecticides have been applied.

Noting that $a$ is a constant, $\phi$ and $\theta$ are parameters, and that $\beta_{t}$ is a function of $K_{t-1}$, the density $L_{t+1}$ is defined by the transition function:

$$
L_{t+1}=\mathcal{T}\left(K_{t}, K_{t-1}, L_{t}\right)
$$

where $K_{t}$ is a decision variable and $K_{t-1}$ and $L_{t}$ are state variables.

\section{Yiold}

Groundnut yield consists of groundnut pods and haulms. GLM can reduce the yield of both components if the GLM density exceeds an injury threshold by the end of the last generation during the season. GLM densities of earlier generations are assiumed not to have a direct impact on yield.

Groundnut yield loss is taken to be proportional to GLM density in generation $t=4$, if this density exiceeds the injury threshold:

$D S=\left\{\begin{array}{l}0 \quad \text { if } L_{4}<z \\ \min \left(y, d L_{4}\right) \quad \text { if } \quad L_{4}>z\end{array}\right.$

where:

$D S$ is the damage or loss in pod yield;

$y$ is the groundnut pod yield of a crop undamaged by GLM;

$z \quad$ is the injury threshold, and

$d$ is the groundnut pod loss per hectare caused by one unit of GLM.

The value of haulm loss (DB) caused by GLM attack is proportional to the pod yield loss:

$D B=(D S(y) b$

where $b$ is the value of the haulms of an undamaged crop.

\section{Net returns}

Net returns $(\mathcal{N} R)$ per hectare from a groundnut crop are given by

$$
\begin{aligned}
\mathcal{N} R= & (y-D S)(p-h)+b(1-D S(y)-v \\
& -\sum_{t} S C K_{t}
\end{aligned}
$$

where:

$p \quad$ is the groundnut market price;

$h \quad$ is the harvesting costs per $\mathrm{kg}$ of product;

$v \quad$ is variable costs per hectare that are unaffected by chemical-control decisions, and

$S C$ is the costs per hectare of chemical control.

Thus, $(y-D S)(p-h)$ is the gross returns from groundnut pods evaluated at the farm-gate price, $b(1-D S \mid y)$ denotes the value of the harvested haulms, and the last term on the right-hand side of Equation (8) is the spray costs.

\section{Chemical control of GLM as a dynamic programming problem}

Dynamic programming (DP) is an operations research technique suitable for multistage optimization problems with the following characteristics: (1) the problem can be disaggregated into distinct stages; (2) one or more state variables can assume a number of discrete states in each stage; (3) a decision has to be made in each stage with the effect of transforming the current state into a state of the next stage; (4) the optimal decisions for the remaining stages depend on the given state in the current stage but are independent of the decisions made in previous stages, and (5) given the optimal decisions for each state in a stage, the optimal decisions for all states in the preceding stage are determined by a recursive relationship (Hillier and Lieberman, 1974). DP finds optimal decisions with less computations than exhaustive enumeration and obviates the need for using optima-approximating search methods in conjunction with simulation.

The problem is to find a chemical-control strategy for one groundnut season that determines, for each GLM generation, whether or not a spray is applied, and that maximizes a farmer's net returns. This problem can be disaggregated into $n$ stages where each stage corresponds to a GLM generation. Ignoring for the moment that the survival rate $\beta_{t}$ may be affected by chemical control in the preceding stage, $\left(K_{t-1}\right)$, GLM density can be represented by a variable with $i=1, \ldots, I$ discrete states. The analogue of Equation (5) then is the discrete state transition equation:

$i_{n-1}=T\left(i_{n}, K_{n}\right)$

where $n$ is counted in the opposite direction from $t$ such that if $t=1, \ldots, \tau$ then $n=\tau, \ldots, 1$.

The solution of a DP problem is derived from the immediate returns, $V_{n}(i, K)$, the state transition from $i_{n}$ to $i_{n-1}$, and optimal remaining returns; $f_{n}(i)$, for each state $i$ of a stage $n$. The immediate return $V_{n}(i, K)$ is calculated by the simulation sub-model and is the contribution to total net returns resulting from a particular decision at the current stage $n$. The 
immediate returns in stage 4 at the beginning of the growing season are equal to the variable costs $v$ in Equation (8). In each intermediate stage the immediate returns are either zero or equal to the costs of chemical control. The immediate returns from the first stage, when groundnuts are harvested, are equal to the sum of returns from pods and haulms minus the costs of chemical control in that stage. The optimal remaining returns, $f_{n}(i)$, are the sum of the returns from the remaining stages, given that an optimal decision is followed at each stage. Optimal remaining returns are calculated by the DP submodel using the recursive relation:

$f_{n}\left(i_{n}\right)=\max _{K}\left[V_{n}(i, K)+f_{n-1}\left(i_{n-1}\right)\right]$

Substituting Equation (9) for $i_{n-1}$ yields:

$$
f_{n}\left(i_{n}\right)=\max _{K}\left[V_{n}(i, K)+f_{n-1}\left(T\left(i_{n}, K_{n}\right)\right)\right]
$$

This states that the best chemical-control decision, given a certain level $i$ of GLM infestation in generation $n$, is the one that maximizes the returns from that decision in that generation and the returns from the GLM infestation level it will cause in the next generation. Beginning with $n=0$ and applying Equation (11) recursively ensures maximum returns and optimal decisions over all remaining $n$ generations in a season for any state $i$.

\section{Data and algorithm}

Data for the constants and parameters of the GLM density model (Table 1) were obtained from various field experiments conducted at ICRISAT Centre near Hyderabad, Andhra Pradesh, India. Data for the economic variables of the model were derived from farm management data of 30 landholding households in a village where groundnut is an important cash crop (Binswanger and Ryan, 1980).

We used the program SDYS to solve the model. SDYS flexibly combines simulation and optimization by integrating the simulation of immediate returns and state variable transitions with a DP algorithm. As SDYS uses numerical rather than analytical solution procedures it is unconstrained by the form of the functions used in simulation and it may be extended for stochastic decision problems.

\section{Technical model validity}

According to Gass (1983, p.612), 'Technical validity is the summation of results in terms of model validity, data validity, logical and mathematical validity, and predictive validity'.

Maximizing behaviour of fully informed decisionmakers is generally accepted in the field of economics as a useful approximation of farmers' decisionbehaviour. The difference equation describing leafminer population growth and the population-yield
TABLE 1. Levels of constants and ranges of parameters

\begin{tabular}{|c|c|c|}
\hline Symbol & Description & Value $^{a}$ \\
\hline \multicolumn{3}{|c|}{ (a) Constants } \\
\hline$z$ & Injury threshold of GLM & $12 \cdot 106 \mathrm{GLM} / \mathrm{ha}$ \\
\hline$d$ & $\begin{array}{l}\text { Groundnut kernel yield lost per } \\
\text { unit of GLM }\end{array}$ & $0.15 \mathrm{mg} / \mathrm{ha} / \mathrm{GLM}$ \\
\hline$a$ & Growth rate of uncontrolled & 20 \\
\hline$h$ & Harvesting cost of groundnut & $0.15 \mathrm{Rs} / \mathrm{kg}$ \\
\hline$v$ & $\begin{array}{l}\text { Variable cost of groundnut (seed, } \\
\text { fertilizer, labour) }\end{array}$ & $1485 \mathrm{Rs} / \mathrm{ha}$ \\
\hline$s$ & $\begin{array}{l}\text { Costs of spraying } 1 \cdot 25 \mathrm{l} / \mathrm{ha} \\
\text { dimethoate }\end{array}$ & $215 \mathrm{Rs} / \mathrm{ha}$ \\
\hline$y$ & $\begin{array}{l}\text { Seed yield of a groundnut crop } \\
\text { undamaged by GLM }\end{array}$ & $1800 \mathrm{~kg} / \mathrm{ha}$ \\
\hline$b$ & $\begin{array}{l}\text { Value of the by-product from an } \\
\text { undamaged groundnut crop }\end{array}$ & $400 \mathrm{Rs} / \mathrm{ha}$ \\
\hline \multicolumn{3}{|c|}{ Parameters } \\
\hline$\Phi$ & Initial GLM density & $2000-40000 \mathrm{GLM} / \mathrm{ha}$ \\
\hline$\theta$ & $\begin{array}{l}\text { Fraction of GLM population } \\
\text { destroyed by chemical control }\end{array}$ & $0.6-0.95$ \\
\hline$\phi$ & $\begin{array}{l}\text { Fraction of GLM population } \\
\text { undamaged by varietal resistance } \\
\text { (level of host plant resistance) }\end{array}$ & $0: 2-1$ \\
\hline$\gamma$ & $\begin{array}{l}\text { Fraction of GLM population } \\
\text { destroyed by natural enemies } \\
\text { when the latter are not damaged } \\
\text { with insecticides }\end{array}$ & $0 \cdot 2-1$ \\
\hline$\alpha$ & $\begin{array}{l}\text { Damage to natural enemies from } \\
\text { insecticides }\end{array}$ & 0.4 and 1 \\
\hline$p$ & Market price of groundnut & 4 and $6 \mathrm{Rs} / \mathrm{kg}$ \\
\hline
\end{tabular}

${ }^{a}$ Prices and costs are in Indian Rupees (Rs)

TABLE 2. Treatment of parameters used in the scenarios

\begin{tabular}{cllllll}
\hline & \multicolumn{5}{c}{ Parameter $^{a}$} \\
$\begin{array}{c}\text { Scenario } \\
\text { no. }\end{array}$ & $\Phi$ & $\phi$ & $\gamma$ & $\alpha$ & $\theta$ & $p$ \\
\cline { 2 - 7 } & $\mathrm{C}^{b}$ & $\mathrm{P}^{b}$ & $\mathrm{P}$ & $\mathrm{I} \cdot 0$ & $\mathrm{C}$ & $\mathrm{P}$ \\
\hline 1 & $\mathrm{P}$ & $\mathrm{P}$ & $\mathrm{P}$ & $1 \cdot 0$ & $\mathrm{C}$ & $\mathrm{C}$ \\
2 & $\mathrm{P}$ & $\mathrm{P}$ & $\mathrm{P}$ & $1 \cdot 0$ & $\mathrm{P}$ & $\mathrm{C}$ \\
3 & $\mathrm{C}$ & $\mathrm{P}$ & $\mathrm{P}$ & 0.4 & $\mathrm{C}$ & $\mathrm{C}$ \\
4 & & & & & & \\
\hline
\end{tabular}

${ }^{a} \Phi$ Initial GLM density; $\phi$ host-plant resistance; $\gamma$ escape from natural enemies; $\alpha$ impact of spray on beneficial insects; $\theta$ spray efficacy; $p$ market price of groundnut. ${ }^{b} \mathrm{C}$, constant; $\mathrm{P}$, parametric over a range

loss relationship are considered acceptable in the absence of data for statistically estimated relationships. The records of farmers' yields, costs and groundnut prices have been collected by experienced investigators from a panel of households in a village, representative of a larger area in the semiarid tropics of India. The DP algorithm was used by Dudley in several other, unrelated studies and only the code of the simulation sub-model was verified. The available time-series of leafminer population records was too short to attempt a meaningful predictive validation of the model.

\section{Scenarios and results}

The questions posed at the end of the 'problem' section (page 350) were answered by defining a 
number of scenarios (Table 2) for the parameters in Table 1. Scenario 1 allows us to evaluate the interactions between HPR, MNE, and the market price of groundnut pods. In scenario 2, the emphasis is on the interactions between initial GLM density, HPR, and MNE. Scenario 3 differs from scenario 2 in that efficacy of chemical control, which is constant in scenario 2, is parametrized. In scenario 4, we evaluated the effects of depleting beneficial insects with insecticide application.

The results are presented in terms of the optimal number of sprays for two reasons. Firstly, there is close to a $1: 1$ correspondence between the number of sprays and the net returns. This is because of the narrow range of GLM densities over which yield reductions of less than the potential yield can occur. This narrow range, combined with the number of sprays being of necessity an integer, usually resulted in either a harvest of the potential yield or a total loss of the crop. The second reason is that reducing farmers' dependence on chemical control is an important objective of HPR research.

\section{Effect of host-plant resistance, natural enemies and market price}

With the first scenario we determined the level of HPR required to offset the need for applying insecticides at a given level of initial GLM density $\Phi=$ $20000 \mathrm{GLM} / \mathrm{ha}$. Because both HPR and MNE reduce GLM density growth, both parameters $\phi$ and $\beta$ were varied in this scenario. Effects on natural enemies of spraying were ignored $(\alpha=1)$ and the kill efficacy of spraying was set at a high level $(\theta=0.95)$.

Table 3 shows that two insecticide applications would be necessary in the absence of HPR and MNE. With no MNE, HPR would have to be $80 \%$ to obviate the need for insecticide application. If the objective of HPR breeding was to offset at least one of two insecticide applications, quantifying breeding objectives in terms of level of HPR would require measurement of $\mathrm{MNE}$ in the range $0<\gamma<0.6$. Conversely, if MNE is as high as 0.8 , then no HPR would be necessary.

The model runs for this scenario were repeated for higher groundnut market prices. The optimal number of sprays was, however, largely unresponsive to price changes in the range of $4<p<6$. Market price was therefore held constant at $p=4$ in the subsequent scenarios.

\section{Effect of initial GLM density and mortality factor}

In this scenario we evaluated the interaction between initial density, HPR, and MNE in terms of the optimal number of chemical controls. To facilitate presentation and discussion of results, the compound effect on GLM growth of HPR and MNE is represented by a GLM mortality factor $\left(1-\phi \beta_{t}\right)$. The initial density $\Phi$ was increased from $5000 \mathrm{GLM} / \mathrm{ha}$ to $40000 \mathrm{GLM} / \mathrm{ha}$ in steps of 5000 . In addition, a very low initial GLM density of $2000 \mathrm{GLM} / \mathrm{ha}$ was assumed. We then determined for each initial GLM density those levels of the mortality factor $\left(1-\phi \beta_{t}\right)$ at which the number of sprays could be reduced by one.

The 'spray mountain' in Figure 1 indicates that three spray applications are optimal when initial densities are high $(\Phi>30000 \mathrm{GLM} / \mathrm{ha})$ and mortality factors are low $(<0.04)$. Mortality from HPR or MNE would have to be high $(>0.8)$ to replace chemical control completely.

The plateaux and escarpments of the spray mountain in Figure 1 are of particular interest for guiding future research. A large plateau at the level of two sprays extends from about 15000 to $40000 \mathrm{GLM} / \mathrm{ha}$ and a mortality factor from about 0.5 to 0 . This plateau indicates that for this range of initial density

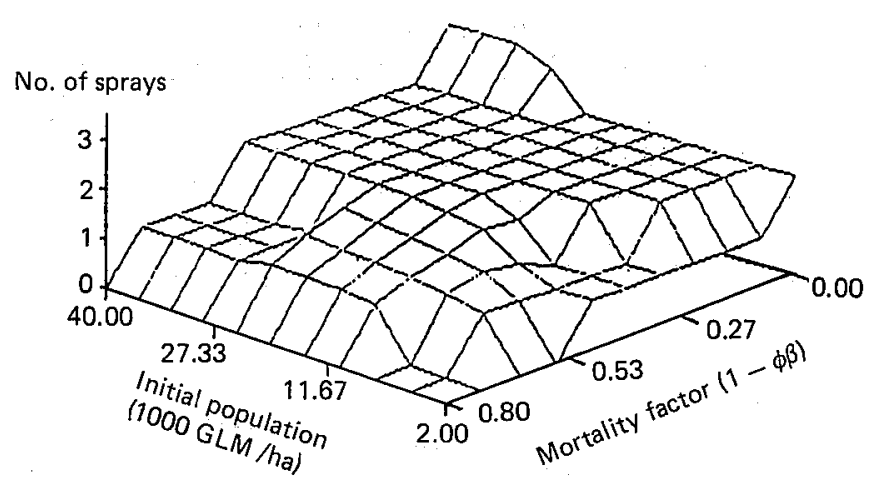

Figlre 1. Number of sprays as a function of initial density and mortality factor of groundnut leafminer (GLM) $(\theta=0.95)$

TABLE 3. Optimal number of sprays as a function of host-plant resistance and mortality from natural enemies ${ }^{a}$

\begin{tabular}{|c|c|c|c|c|c|c|c|c|c|c|}
\hline \multirow{2}{*}{$\begin{array}{l}\text { Level of } \\
\text { natural } \\
\text { mortality } \\
\quad(\gamma)\end{array}$} & \multicolumn{10}{|c|}{ Level of host-plant resistance $(\phi)$} \\
\hline & 0 & 0.1 & 0.2 & 0.3 & 0.4 & 0.5 & 0.6 & 0.7 & 0.8 & 0.9 \\
\hline 0 & 2 & 2 & 2 & 2 & 2 & 1 & 1 & 1 & 0 & 0 \\
\hline $0 \cdot 2$ & 2 & 2 & 2 & 2 & 1 & 1 & 1 & 0 & 0 & 0 \\
\hline 0.4 & 2 & 2 & 1 & 1 & I & 1 & 0 & 0 & 0 & 0 \\
\hline 0.6 & l & 1 & 1 & 1 & 0 & 0 . & 0 & 0 & 0 & 0 \\
\hline 0.8 & 0 & 0 & 0 & 0 & 0 & 0 & 0 & 0 & 0 & 0 \\
\hline
\end{tabular}

$\Phi=20000 ; \alpha=1, \theta=0.95, p=4$ 
and a given level of MNE, which is compatible with the range of the mortality factor, introducing more HPR into groundnut cultivars may not reduce the number of sprays required. Conversely, the plateaux may be interpreted as areas for which exact knowledge of mortality from natural enemies may not be required. For example, at levels of initial density beyond $15000 \mathrm{GLM} / \mathrm{h}$ a and when HPR is $80 \%$, the fraction of GLM escaping natural enemies could vary between $50 \%$ and $100 \%$ without having an effect on the optimal number of sprays. However, if initial density levels are lower than $15000 \mathrm{GLM} / \mathrm{ha}$, relatively small changes in HPR and MNE will influence the optimal number of sprays.

The interdependence between initial density and the mortality factor is more clearly presented in Figure 2 where the contour lines A, B, and C demarcate areas of equal numbers of optimal sprays. For example, the area between contours B and C comprises all combinations of initial density and mortality factor that would require two insecticide applications. It is clear from Figure 2 that the optimal number of sprays for given levels of HPR and MNE is quite insensitive to changes in the initial density, once the initial density exceeds $15000 \mathrm{GLM} / \mathrm{ha}$.

\section{Effect of chemical-control efficacy}

A high level of chemical-control efficacy $(\theta=0.95)$ was assumed in the previous scenarios. Although some farmers may be able to achieve this level, it is unlikely that it is the average. Unfortunately, we do not know of any relevant report of the level of chemical-control efficacy in farmers' fields. To evaluate the effect of chemical-control efficacy on the optimal number of sprays, we varied $\theta$ in the range from 0.95 to 0.60 and determined the levels of the mortality factor $\left(1-\phi \beta_{t}\right)$ at which the optimal number of chemical controls changed. This evaluation was carried out for three levels of initial density, i.e. $\Phi=5000,20000$ and $35000 \mathrm{GLM} / \mathrm{ha}$.

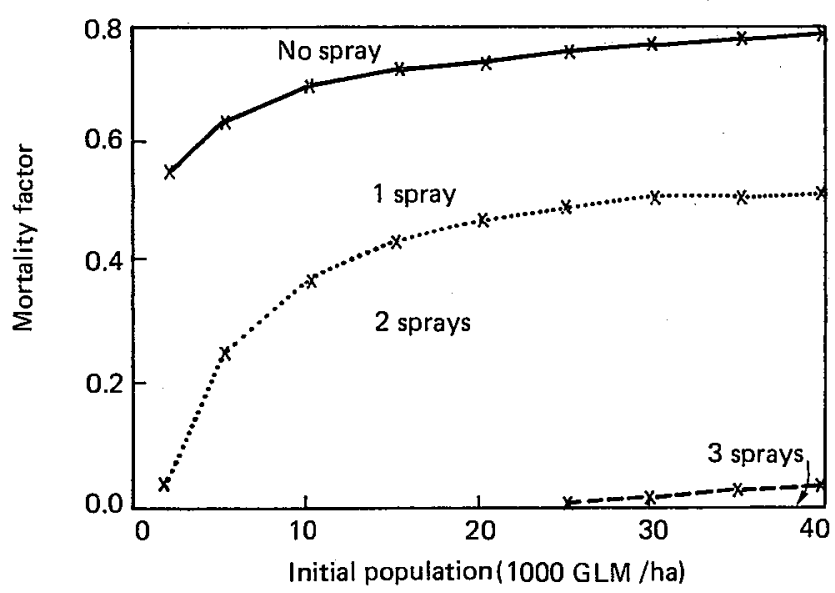

FigLre 2. Contour lines for areas of equal number of sprays as a function of initial density and mortality factor of GLM. $---, \mathrm{C}$

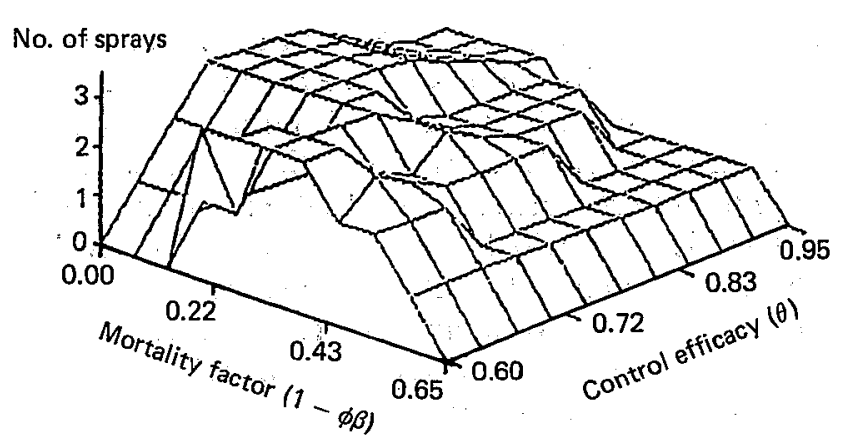

FIGURE 3. Number of sprays as a function of mortality factor and control efficacy (initial density $\Phi=5000 \mathrm{GLM} / \mathrm{ha}$ )

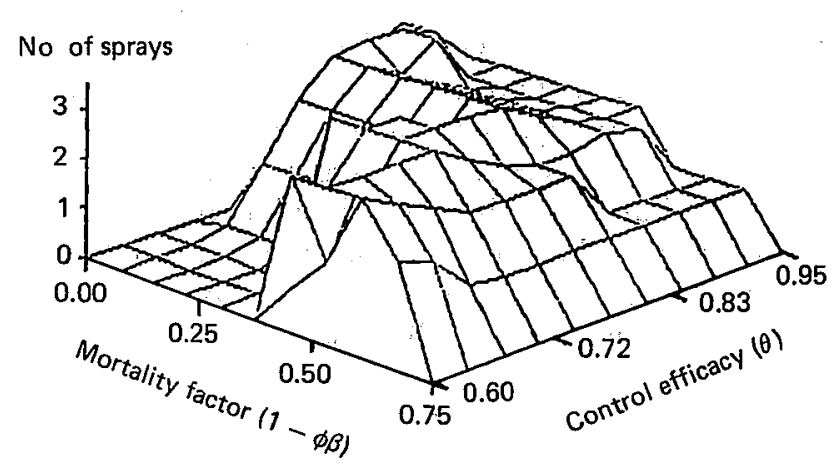

FIGLRE 4. Number of sprays as a function of mortality factor and control efficacy (initial density $\Phi=20000 \mathrm{GLM} / \mathrm{ha}$ )

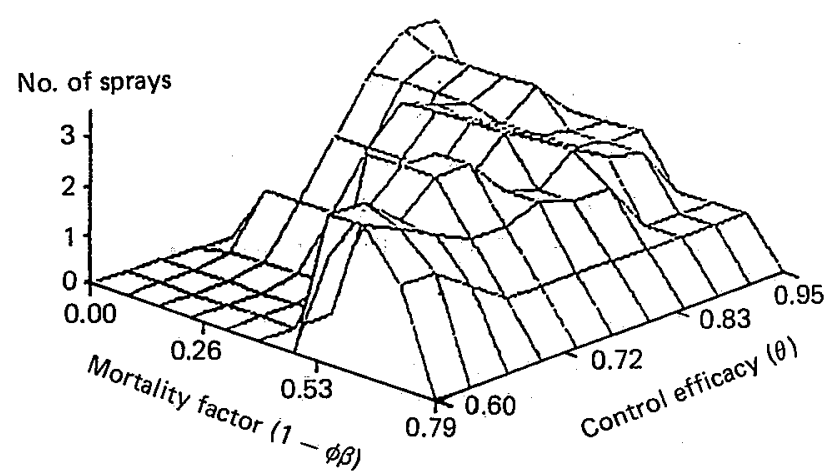

FIGLRE 5. Number of sprays as a function of mortality factor and control efficacy (initial density $\Phi=35000 \mathrm{GLM} / \mathrm{ha}$ )

Comparison of the spray-response mountains in Figures 3, 4, and 5 with Figure 1, where a constant chemical-control efficacy of 0.95 was assumed, indicates the sensitivity of the optimal number of sprays to changes in control efficacy. The response mountains do not have extensive plateaux but are fairly rugged with many escarpments. Furthermore, the areas of the plateaux decline with increasing initial density levels, indicating the increasing sensitivity of the optimal number of sprays to changes in control efficacy. Figures 4 and 5 show depressions at the south-west foot of the spray mountains. These depressions are characterized by low mortality factors and low control efficacy, implying that GLM density growth is little reduced by either HPR or MNE and that many GLM survive insecticide application. With poor control and relatively high initial 
density levels, these depressions indicate that the crop would be devastated, even if insecticides were applied. In such situations chemical control would only add to farmers' losses, and groundnut should not be grown.

Figures 6,7 and 8 represent the contour maps for the response mountains in Figures 3, 4 and 5, respectively. The areas between the contour lines again represent combinations of control efficacy and density growth reduction from HPR that result in equal numbers of sprays, given a level of initial density. These contour maps highlight the need to know the efficacy of chemical control in farmers' fields for determining the objectives of a HPR breeding programme. For example, when $20 \%$ of the GLM are destroyed by natural enemies $(\gamma=0.2)$ and with an initial density of $5000 \mathrm{GLM} /$ ha (Figure 6), farmers could grow groundnut as long as their chemicalcontrol efficacy is higher than 0.6 , even if the cultivar has no HPR. All farmers who achieve a control efficacy between 0.6 and 0.8 would optimally apply three sprays and only farmers who achieve a level of control efficacy higher than 0.8 would optimally spray less than three times. If a moderate level of HPR, e.g. $\phi=0.75$, is introduced, the mortality factor is increased to 0.4 . At that level of mortality

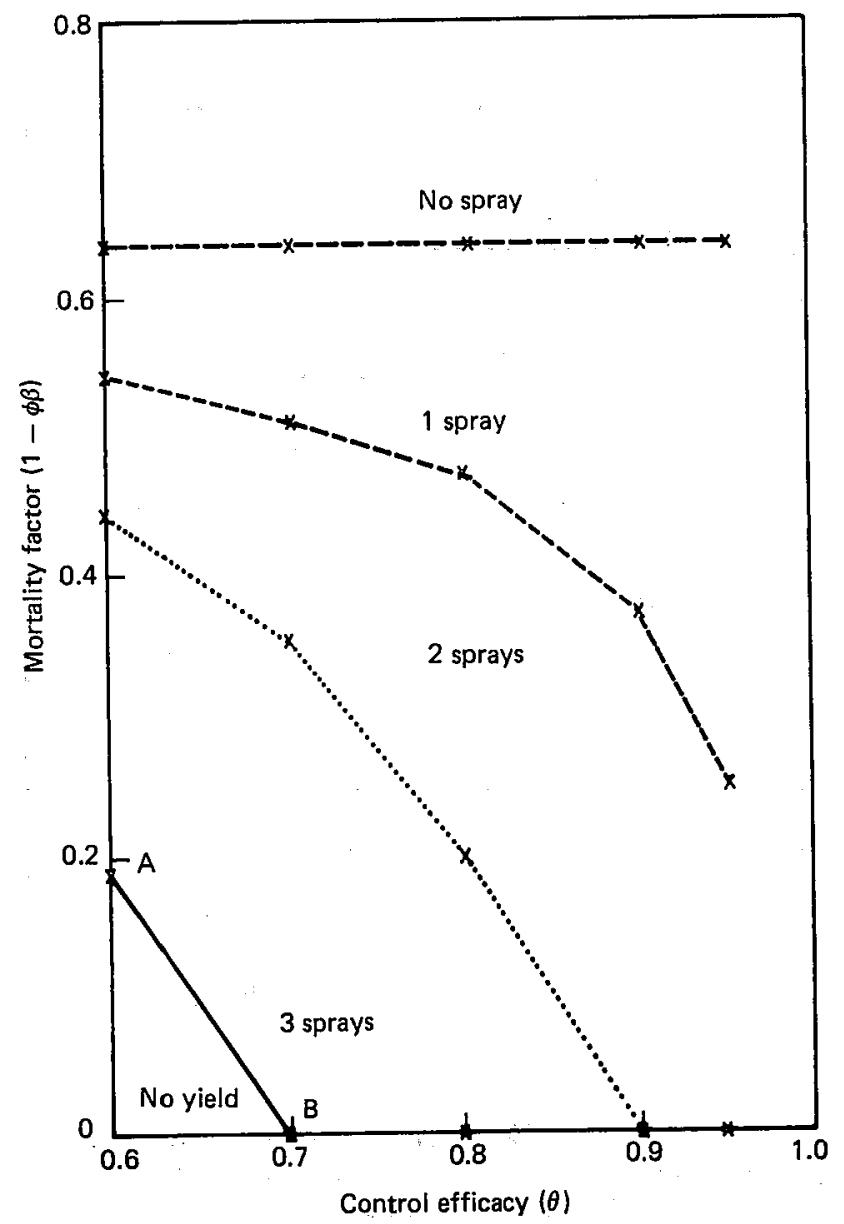

FIGURE 6. Contour lines demarcating areas of optimal number of sprays as a function of control efficacy and mortality (initial density $\Phi=5000 \mathrm{GLM} / \mathrm{ha}$ )

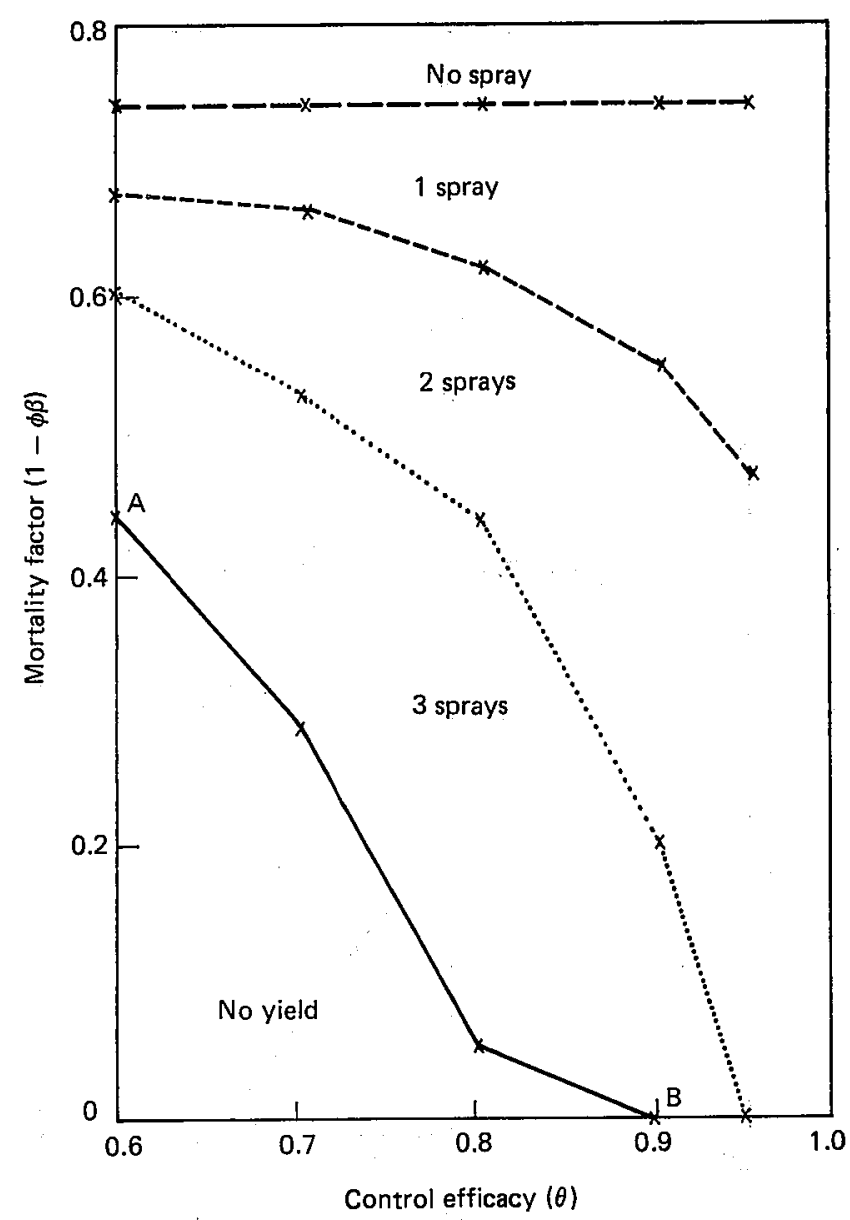

FIGURE 7. Contour lines demarcating areas of optimal number of sprays as a function of control efficacy and mortality factor (initial density $\Phi=20000 \mathrm{GLM} / \mathrm{ha}$ )

the number of sprays could be reduced from three to two when the control efficacy is 0.65 , and further reduced to one when control efficacy reaches $0 \cdot 87$.

The trade-off between HPR and control efficacy at given levels of MNE is indicated by the slopes of the contours in Figures 6, 7 and 8 . The steeper the contour, the higher must be the increase in HPR to offset a reduction in chemical-control efficacy. For example, the contour in Figure 8, that demarcates the no-spray from one-spray areas, is horizontal, indicating that the optimal number of sprays is insensitive to chemical-control efficacy once the mortality factor reaches 0.79 . The slope of the contour demarcating the areas of three and two optimal sprays flattens when the control efficacy exceeds $0 \cdot 8$, indicating that higher increases in HPR are required to offset reductions in chemical-control efficacy when the level of the latter is higher than 0.8 .

The slopes of the contours in Figures 6,7 and 8 are flatter at higher mortality levels. If the distribution of farmers by chemical-control efficacy is approximately uniform, then at a given level of MNE, the number of farmers benefiting from the same increase in HPR will be larger at high levels of HPR than at low levels. The shape of the contours also implies that MNE not only helps individual farmers to 


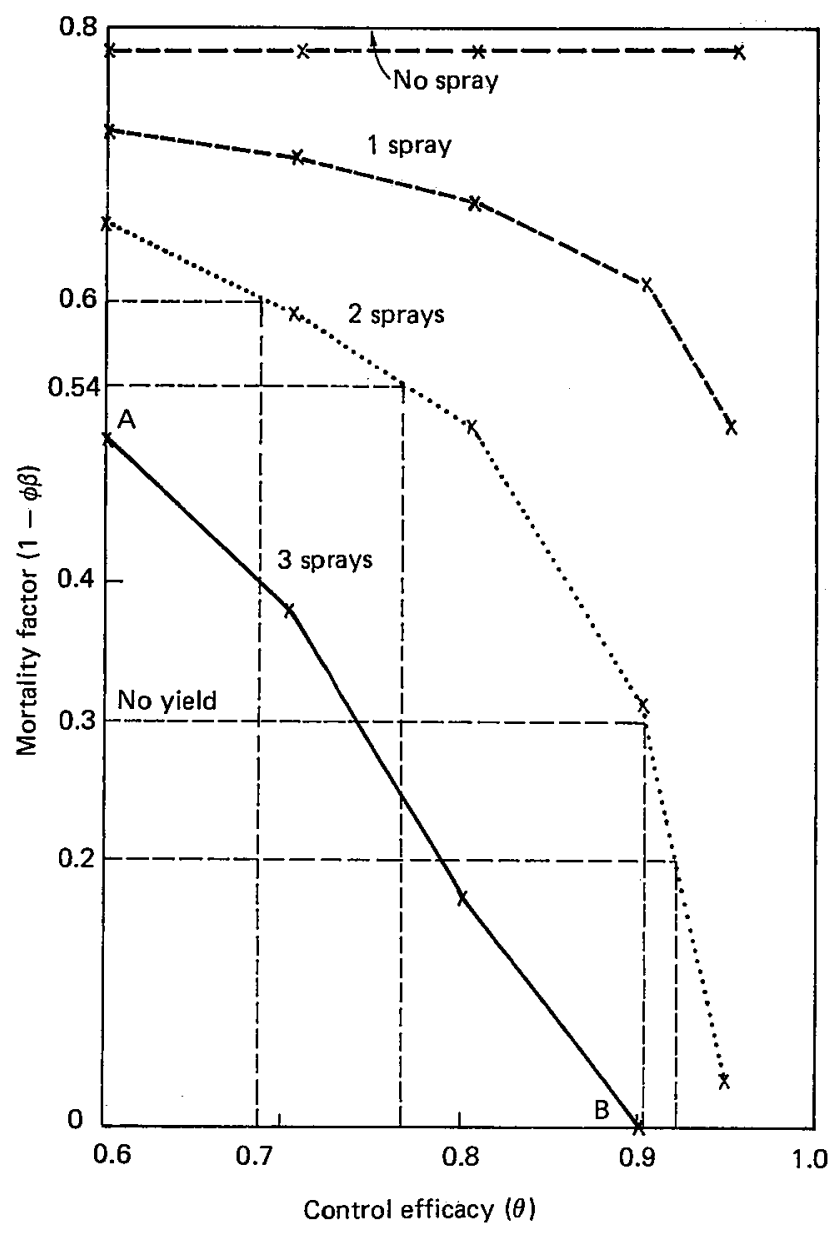

FiglRe 8. Contour lines demarcating areas of optimal number of sprays as a function of control efficacy and mortality factor (initial density $\Phi=35000 \mathrm{GLM} / \mathrm{ha}$ )

control GLM, but also that it may contribute to increasing considerably the number of beneficiaries from a HPR breeding programme. For example, consider the contour lines separating the areas for three and two sprays in Figure 8 . If, in the absence of MNE $(\beta=1)$, HPR is increased by 10 percentage points, from $\theta=0.8$ to $\theta=0.7$, the mortality factor will also increase by 10 percentage points, from 0.2 to 0.3 . This increase in HPR will allow all farmers with control efficacies in the range $0.9<\theta<0.92$ to reduce their optimal numbers of sprays from three to two. In the presence of MNE, e.g. $\beta=0.57$, a mortality factor of 0.54 obtains when $\phi=0.8$. If HPR is now increased by 10 percentage points, the mortality factor increases to $0 \cdot 6$. This increase will allow all farmers with control efficacies in the range $0.69<\theta<0.77$ to reduce the number of sprays from three to two sprays. Unless the distribution of farmers by control efficacy is heavily skewed toward high .control efficacy, more farmers will benefit from increased host-plant resistance when MNE increases until levels of $\mathrm{MNE}$ are reached where no sprays are necessary.

Figures 6,7 and 8 illustrate the effects of initial density under conditions where groundnuts either should not be grown or need not be treated with insecticides. The area $\mathrm{OAB}$ indicates the conditions of mortality and control efficacy under which groundnut should not be grown. As expected, these areas increase with increasing initial density. Furthermore, the level of mortality that must be achieved to make spraying unnecessary increases from 0.62 at low levels of initial density, to 0.67 at medium initial densities, and reaches 0.79 at the highest initial density of $40000 \mathrm{GLM} / \mathrm{ha}$.

\section{Effect of insecticide damage to beneficial insects}

We have assumed that insecticide application does not reduce the effects of MNE. We ran the model for a small range of parameters with and without an
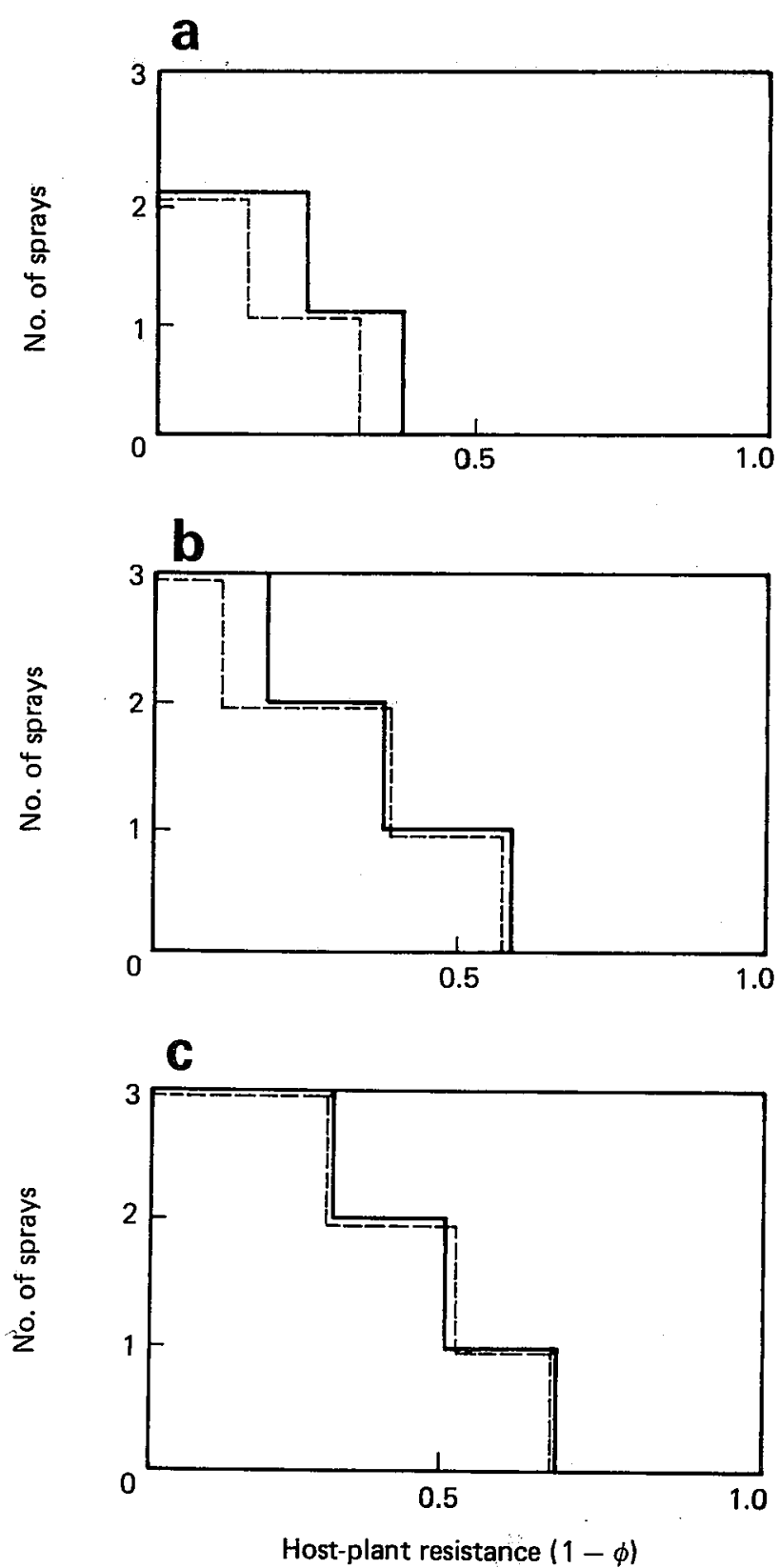

FIGURE 9. Optimal number of sprays at different levels of mortality from natural and host-plant resistance with and without delayed damage to natural enemies by pesticides. $\gamma=$ (a) 0.4 ; (b) 0.6 ; (c) 0.8 . $-\alpha=0.4$ (effect of spray on MNE); - $--\alpha=1$ (no effect of spray on MNE) 
insecticide effect on beneficial insects. We accounted for the insecticide effect on beneficial insects by reducing the mortality from natural enemies, i.e. $\gamma$ in the period after insecticide application to $40 \%$ (i.e. $\alpha=0.4$ ) of what it would have been had no insecticide been applied. In these model runs we assumed an initial GLM density of $20000 \mathrm{GLM} / \mathrm{ha}$ and a chemical-control efficacy of $\theta=0 \cdot 8$.

Model results (Figure 9) corroborate what was expected. When MNE is high, more HPR is required to maintain the same number of sprays when beneficial insects have been affected by insecticide applied to the previous GLM generation, compared with a situation where beneficial insects are not damaged by insecticides. This effect is negligible when MNE is low.

\section{Discussion and conclusions}

By determining the optimal number of chemicalcontrol applications by dynamic programming for simulated groundnut leafminer densities and crop net returns, we were able to evaluate the trade-offs between important variables affecting leafminer density growth and crop net returns from groundnut. The variables considered were groundnut price, host-plant resistance, mortality from natural enemies, chemical-control efficacy in farmers' fields, delayed effect on natural enemies from chemical control, and leafminer densities at the beginning of the groundnut season.

Model results indicated that the optimal number of sprays is insensitive to changes in groundnut price over a wide range of host-plant resistance and mortality from natural enemies. The optimal number of sprays is high and insensitive to changes in initial pest densities in the range from 15000 to 40000 pests per hectare when host-plant resistance, or mortality from natural enemies, are low.

The sensitivity of the optimal number of sprays to resistance, or mortality from natural enemies, is increased when chemical-control efficacy is reduced. Critical levels of initial GLM density, chemicalcontrol efficacy and mortality from natural enemies, that are detrimental to growing groundnuts, were quantified.

The importance of natural enemies for the potential benefits from cultivars with increased host-plant resistance was emphasized. These benefits are likely to be higher, the lower is farmers' chemical-control efficacy and, unless very high levels of efficacy prevail, the higher is the mortality from natural enemies. Models, such as ours, can be regarded as complicated 'tautology machines' that do not yield any new facts, but only explore the implications hidden in the data and assumptions used in model specification. In our case, the hidden implications emphasize the need for better information on chemical-control efficacy, on leafminer mortality from natural enemies in farmers' fields and on the infestation-yield relationship. Unless more is known about these variables, objectives for host-plant resistance cannot be reliably quantified and breeding effort is likely to be wasted.

\section{Acknowledgements and notes}

The authors are grateful to R. Hari Haran for executing the several thousand model runs and for preparing the graphs. Various colleagues, J. M. Peacock in particular, and anonymous reviewers made helpful comments on earlier drafts.

ICRISAT JA No. 741.

\section{References}

Binswanger, H. P. AND RYAN, J. G. (1980). Village-level studies as a locus for research and technology adaptations. In: Proceedings of the International Symposium on Development and Transfer of Technology for Rainfed Agriculture and the SAT Farmer, 28 August-1 September 1979, ICRISAT, Hyderabad, India, pp. 121-129. Patancheru, A.P. 502 324, India: International Crops Research Institute for the Semi-Arid Tropics.

Feldman, R. M. AND GurRY, G. L. (1982). Operations research for agricultural pest management. Operations Research 30, 601-618.

Gass, S. I. (1983). Decision-aiding models: validation, assessment, and related issues for policy analysis. Operations Research 31, 603-631.

Hillier, F. S. ANd Lieberman, G. J. (1974). Operations Research, 2nd edn. San Francisco: Holden-Day. 800 pp.

ICRISAT (1986). Annual Report 1985. Patancheru, A.P. 502 324, India: ICRISAT (International Crops Research Institute for the Semi-Arid Tropics).

KENNEDY, J. O. S. (1981). Applications of dynamic programming to agriculture, forestry and fisheries: review and prognosis. Review of Marketing and Agricultural Economics 49, 141-173.

Mohammad, A. (1981). The Groundnut Leafminer, Aproaerema modicella, Deventer (Stomopteryx subsecivella, Zeller) (Lepidoptera: Gelechiidae): A Review of World Literature. Patancheru, A.P. 502 324, India: IGRISAT (International Crops Research Institute for the Semi-Arid Tropics). (Limited circulation)

Onstad, D. W. AND RabBinge, R. (1985). Dynamic programming and the computation of economic injury levels for crop disease control. Agricultural Systems 18, 207-226.

ShoEMAKER, C. A. AND ONSTAD, D. W. (1983). Optimization analysis of the integration of biological, cultural, and chemical control of alfalfa weevil (Coleoptera: Curculionidae). Environmental Entomology 12, 286-295.

TAYLOR, G. R. AND BURT, O. R. (1984). Near-optimal management strategies for controlling wild oats in spring wheat. American Journal of Agricultural Economics 66, 50-60.

Wightman, J. A. AND Amin, P. W. (1988). Groundnut pests and their control in the semi-arid tropics. Tropical Pest Management 34, 218-226.

Received 22 February 1988

Revised 29 August 1988

Accepted 27 January 1989 